BNL-99797-2013-IR

\title{
Exploding Pressure Vessel Test of YBaCuO HTS Pancakes
}

\author{
Holger Witte, Lakshmi Lalitha, Ramesh Gupta, Richard Lewin, \\ Harry Jones, and Anthony Hickman
}

February 2013

Physics Department

Brookhaven National Laboratory

\section{U.S. Department of Energy Office of Science}

Notice: This manuscript has been authored by employees of Brookhaven Science Associates, LLC under Contract No. DE-AC02-98CH10886 with the U.S. Department of Energy. The publisher by accepting the manuscript for publication acknowledges that the United States Government retains a non-exclusive, paid-up, irrevocable, world-wide license to publish or reproduce the published form of this manuscript, or allow others to do so, for United States Government purposes. 


\section{DISCLAIMER}

This report was prepared as an account of work sponsored by an agency of the United States Government. Neither the United States Government nor any agency thereof, nor any of their employees, nor any of their contractors, subcontractors, or their employees, makes any warranty, express or implied, or assumes any legal liability or responsibility for the accuracy, completeness, or any third party's use or the results of such use of any information, apparatus, product, or process disclosed, or represents that its use would not infringe privately owned rights. Reference herein to any specific commercial product, process, or service by trade name, trademark, manufacturer, or otherwise, does not necessarily constitute or imply its endorsement, recommendation, or favoring by the United States Government or any agency thereof or its contractors or subcontractors. The views and opinions of authors expressed herein do not necessarily state or reflect those of the United States Government or any agency thereof. 


\title{
Exploding Pressure Vessel Test of YBaCuO HTS Pancakes
}

\author{
Holger Witte*1, Lakshmi Lalitha ${ }^{1}$, Ramesh Gupta ${ }^{1}$, Richard Lewin ${ }^{2}$, \\ Harry Jones ${ }^{2}$, and Anthony Hickman ${ }^{2}$ \\ ${ }^{1}$ Brookhaven National Laboratory, P.O. Box 5000, Upton, NY, 11973, USA \\ ${ }^{2}$ University of Oxford, Clarendon Laboratory, Oxford, OX1 3PU, UK
}

February 22, 2013

A potential future muon collider requires high field solenoids of $30 \mathrm{~T}$ or more in the final cooling section. The Magnet Division at Brookhaven National Laboratory has an active research programme to realize this using high temperature superconductors. A two coil system is presently being build which is designed to produce $20 \mathrm{~T}$ or more. The coil design uses a commercially available $\mathrm{YBaCuO}$ superconductor from SuperPower.

It is common practice to co-wind the HTS tape with stainless steel tape. This is done to provide additional reinforcement to counterbalance the high Lorentz forces at high fields. In addition, the steel tape can be seen as an insulation due to the high resistivity.

The steel/HTS structure is not impregnated with epoxy resin, which means that it is not clear if classical composite theory applies in this case. Bulk parameters, obtained using the rule of mixtures or the Halphin-Tsai equations, are potentially incorrect. A further question is that of mechanical slippage: the friction coefficient between the steel and HTS tape can be assumed to be very small (metal to metal), so it is not unreasonable to assume that the pancake may unwind under load and thus withstand much smaller forces and fields.

To investigate this an existing experimental setup was used, which is named 'exploding pressure vessel test'. This material test is ideally suited to investigate this, as it allows to subject materials to loading conditions very similar to that experienced in solenoids in a controlled way. This report describes the experimental setup and initial results obtained in June 2012.

*hwitte@bnl.gov 


\section{Introduction}

A muon collider is regarded as one of the presently most attractive options for experiments at unprecedented center of mass energies. In comparison to other competing lepton collider designs, for example ILC or CLIC, a Muon Collider is smaller while at the same time delivering more than twice the center of mass energy. A further advantage is the much lower required wall-power.

However, many sub-systems of a potential future muon collider are technologically very challenging: this primarily stems from the short lifetime of muons, which dictates fast acceleration. At present there are various ongoing activities to demonstrate the feasibility of the different sub-systems.

One of the most challenging parts of a future muon collider is high field solenoids in excess of 30T for the final cooling of the muons. In principle $30 \mathrm{~T}$ can be generated using normal conducting water-cooled electromagnets, but this is very costly in terms of energy consumption. More efficient is the use of high temperature superconductors (HTS), which can operate in these field levels.

Currently BNL has an active research programme aiming to deliver a two coil, all-HTS 20T solenoid [3, 8]. The solenoids employ commercially available $\mathrm{YBaCuO}$ tape from SuperPower 1 .

One of the unanswered questions in this respect is the behaviour of HTS pancakes at high mechanical loads, which can be expected at the 20-30T level. The HTS tape is co-wound with stainless steel tape for strength reasons and insulation purposes; this is common practise and has been shown to work in many fabricated single and double pancakes.

This report is an attempt to study the deformation behaviour of pancakes under a controlled loading condition similar to that experienced by a real pancake in a magnet. A particular focus is on potentially arising unraveling of the pancake, as the HTS/steel structure is usually not impregnated with epoxy resin. It is therefore conceivable that the friction between HTS and steel tape is not large enough to withstand the force aiming to unroll the pancake.

The next section deals with a brief theoretical treatment; the following sections describe the experimental setup used for the experimental investigation and the test results.

\section{Theoretical Approach to Friction between HTS Tape and Steel Insulation}

To estimate if the friction between HTS and steel tape are sufficient to withstand a certain radial force we can do a simple thought experiment. Let's consider two turns of an arbitrary material, which are loaded to a stress level $\sigma$ of $500 \mathrm{MPa}$, which is similar to what an HTS tape might experience in a 20-30T magnet.

\footnotetext{
${ }^{1}$ SuperPower Inc., 450 Duane Avenue, Schenectady , NY, 12304, USA
} 
Let $t$ and $w$ be the thickness and the width of the HTS tape; we can now do the thought experiment of cutting the tape and evaluate the force $F$ which is required to hold both ends of the tape:

$$
F=\sigma \cdot t \cdot w=200 \mathrm{~N}
$$

In order to avoid slipping of the tape a normal force $F_{N}$ has to be applied which is equal or larger to this force $F$ :

$$
F_{\mathrm{N}}=\frac{F}{\mu} .
$$

In this equation $\mu$ is the friction coefficient, which we assume to be 0.2 , which is a common value for a steel-steel contact. Therefore, to avoid slipping the minimum required force is $1000 \mathrm{~N}$, or a uniform pressure of about $0.8 \mathrm{MPa}$ assuming an inner radius of $50 \mathrm{~mm}$ and a tape width of $4 \mathrm{~mm}$.

The theoretical treatment shows that a very small outer pressure is required to prevent slippage of a HTS/steel pancake, which can easily be provided by applying pre-stress to the tape.

\section{Description of the Exploding Pressure Vessel Setup}

To investigate this experimentally a setup known as the 'exploding pressure vessel' (or explo for short) was employed [6, 11]. The main component of the explo setup is a copper cell, which in its most simple form is a hollow cylinder.

The copper cell is axially fixed by an outer steel clamp. The material which is tested is wound onto the outside of the cylinder and suitably instrumented using strain gauges. For the experiment the cell is pressurized, in the original version using oil. The copper cell is fully annealed and therefore deforms almost entirely plastically. The copper shell then loads the material to be tested. The stress in the material can be calculated easily from the applied pressure inside the cell.

While the original version of the explo cell was using oil as a pressurizing medium, a more recent version uses He gas. He gas has the advantage that experiments at lower temperatures $(77 \mathrm{~K}$ or $4 \mathrm{~K})$ can be carried out without solidifying the pressurizing medium. This unique experimental setup is available at Oxford University in the UK. Fig. 1 shows a schematic of the explo cell in the outer clamp.

The $\mathrm{Cu}$ cell used for experiments (a picture is shown in Fig. 2) has in inner diameter of $28 \mathrm{~mm}$, an outer diameter of $44.9 \mathrm{~mm}$ and a winding length of $30.3 \mathrm{~mm}$.

\section{Sample Preparation}

Apart from the superconductor, large fractions of the HTS tape normally consists of copper and hastelloy. The amount of copper is varied for different applications, in order to achieve better performance or stability. For the experiments two different tapes were used, which 


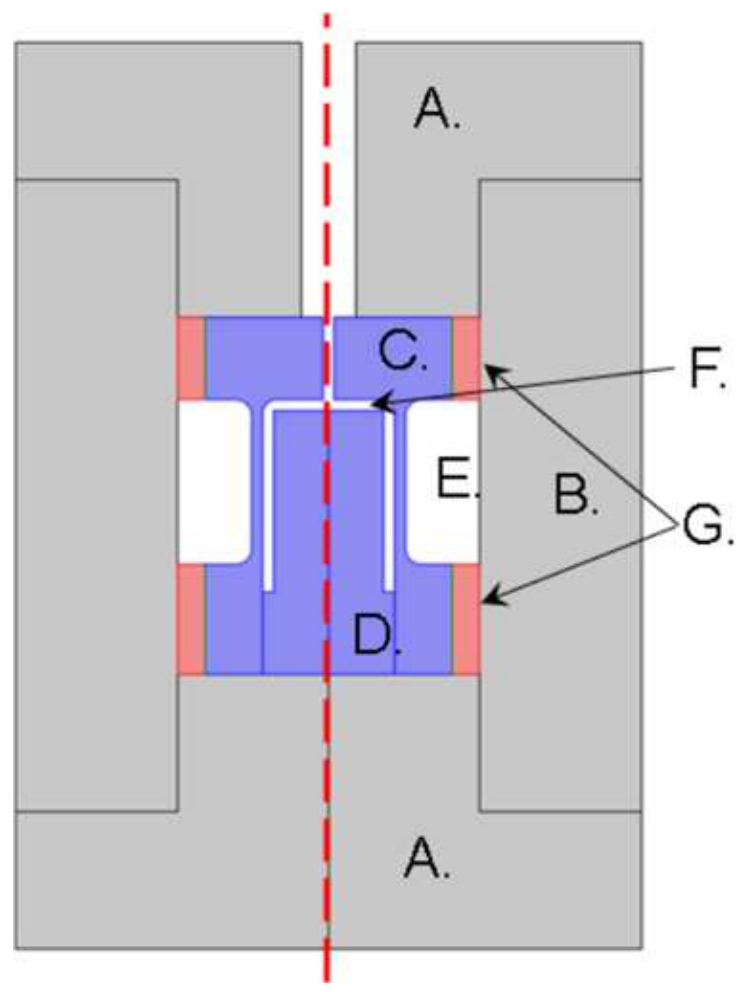

Figure 1: Sketch of the exploding pressure vessel setup. The sketch shows the copper cell (' $\mathrm{C}$ ' and ' $\mathrm{D}$ '), the external stainless steel clamp ('A' and 'B') and additional support rings to center the cell in the clamp (' $G$ '). The sample is wound on the outside of the cell ('E'); the cell is pressurized by thin capillary (not shown) using helium gas in space ' $\mathrm{F}$ '. 


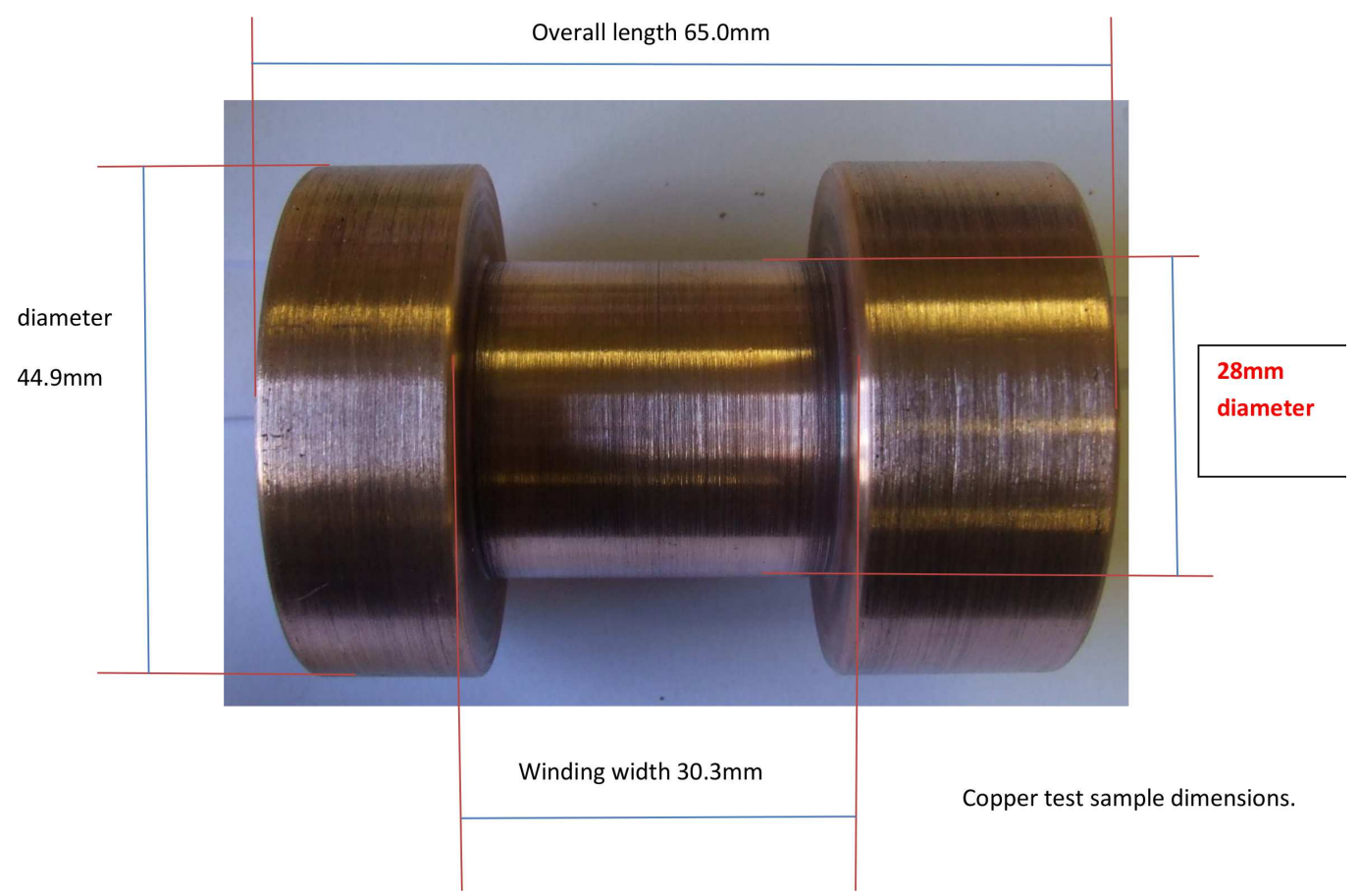

Figure 2: Picture of the copper cell on which the test samples are wound.

have been used for pancakes in high field solenoids. The samples were prepared on a special winding machine which is normally used to wind HTS pancakes. The winding machine allows to control the tension of the HTS tape accurately. Similar to a real pancake the HTS tape is co-wound with AISI 304 stainless steel tape. Each explo former is prepared so that the tape is located in the centre of the winding section.

Samples one, two and three employ a $12 \mathrm{~mm}$ wide tape. The total HTS tape thickness is $162 \mu \mathrm{m}$ with about $100 \mu \mathrm{m}$ copper and $62 \mu \mathrm{m}$ hastelloy. The tape is co-wound with a $50.8 \mu \mathrm{m}$ thick 304 steel tape of the same width. The tapes are wound at the same time with a pretension equivalent to 6 and 7 pounds on HTS and steel tape, respectively. 20 turns in total are wound; subsequently the outside of the pancake is painted with epoxy resin Epon 815C with curing agent Epikure 3140.

Samples four to seven use a $12 \mathrm{~mm}$ wide tape with a total thickness of $120 \mu \mathrm{m}(65 \mu \mathrm{m}$ copper and $55 \mu \mathrm{m}$ hastelloy). The tape is co-wound with a $25.4 \mu \mathrm{m}$ thick 304 steel tape. The pretension on the HTS-tape and steel tape are 6 and 7 pounds, respectively. After winding 29 turns the outside of each pancake is painted with epoxy resin Epon 815C with curing agent Epikure 3140.

The number of turns was chosen so that the radial thickness of the HTS/steel windings is approximately $4.2 \mathrm{~mm}$. Using the rule of mixtures it was estimated that the bursting pressure should be between 1-1.5 kbar. The additional space in the winding section was filled with Zylon, which is a high strength fibre from Toyobo [10]. Subsequently an outer 


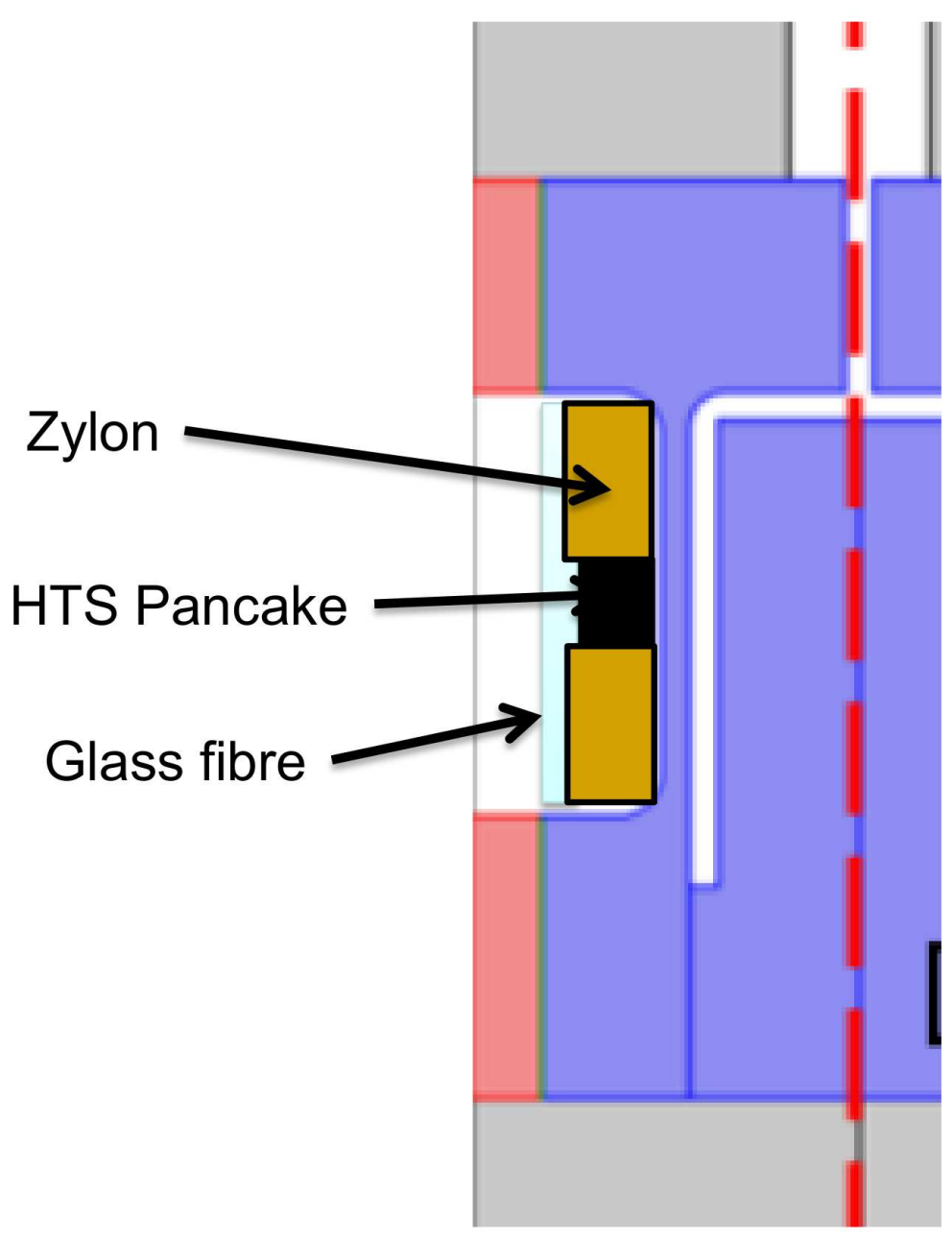

Figure 3: Sketch showing the HTS/steel composite wound on the outside of the cell. The remaining space is filled with a high-strength fibre Zylon. On the outside a $1 \mathrm{~mm}$ thick layer if glass fibre was added.

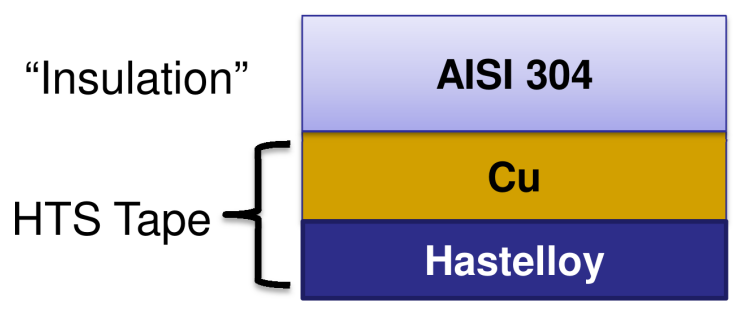

Figure 4: Geometry of the HTS tape / steel insulation. 
layer of glass fibre is added over the entire winding length to provide initial pre-compression. Neither the Zylon fibre nor the glass fibre are impregnated with resin. Strain gauges are attached to the outside of the HTS pancake; the strain gauges (type N11MA512016 from RS Components) have a gauge factor of 2.1 and a nominal resistance of $120 \Omega$. The strain gauges are powered by a stabilized constant current source with a current of $100 \mathrm{~mA}$. The signal is recorded using a NI USB-6211 DAQ data acquisition unit (16-bit, $250 \mathrm{kS} / \mathrm{s}$, absolute accuracy better than $\pm 0.0135 \%$ ). The applied pressure is taken directly from a calibrated pressure gauge of the explo setup.

\section{Finite Element Model}

The measurements are compared with finite element simulations. The finite element simulations are carried out using COMSOL 2, which is a commercial 'Multiphysics' package. For the analysis the structural mechanics application mode is employed, which supports isotropic, anisotropic and non-linear analyses. Isotropic material properties are used for steel and copper of the explo cell; orthotropic material properties are used for the reinforcement fibres (glass and Zylon). Plastic deformation is considered for copper and steel. The application mode supports large deformation, which is essential for this simulation due to the large strains. Thermal effects are not considered. Most of the material properties have been taken from [13].

For copper a bi-linear stress-strain model is employed. The Young's modulus is assumed to be $110 \mathrm{GPa}$ and the Poisson's ratio 0.35. For elasto-plasticity the yield stress is $75 \mathrm{GPa}$ and the tangent modulus $2 \mathrm{GPa}$. In previous analyses it was found that these material parameters are adequate for soft copper [13]. For the HTS tape likewise a bi-linear stressstrain model is used. For the conductor with $100 \mu \mathrm{m}$ copper the Young's modulus is $87 \mathrm{GPa}$, the yield stress is $450 \mathrm{MPa}$ and a tangent modulus is $4 \mathrm{GPa}$ [2]. For the HTS tape with $60 \mu \mathrm{m}$ copper at room temperature $(77 \mathrm{~K})$ the Young's modulus is $120 \mathrm{GPa}$ $(110 \mathrm{GPa})$, the yield stress is $530 \mathrm{MPa}(700 \mathrm{MPa})$ and the tangent modulus is $6.5 \mathrm{GPa}$ $(10 \mathrm{GPa})$. The material properties for S2-glass fibre and Zylon are summarized in tables 1 and 2, For AISI 304 (reinforcement tape) we use the material properties from table 3 .

Fig. 5 shows an overview of the FEA model. Only the inner cell is modelled; for the top and lower face a boundary condition is applied which prevents longitudinal movement. In reality this is ensured by the outer clamp. The figure also shows the winding section, where each layer of HTS tape is supported by a layer of stainless steel tape. In the model a gap is included between the winding section and the reinforcement fibre Zylon.

The strain in the model is evaluated at the same position as in the experiment, which is on the outside of the last turn of the steel reinforcement tape. Fig. 6 shows examples of the analysis; the left figure shows a deformation plot, showing the radial buckling of the conductor/steel section. The Zylon reinforced part of the cell shows little or no deformation.

\footnotetext{
${ }^{2}$ COMSOL AB, Tegnérgatan 23, SE-111 40 Stockholm, Sweden
} 


\begin{tabular}{|l|c|c|}
\hline Property & Value & Unit \\
\hline \hline $\mathrm{E}_{\|}$ & 55 & $\mathrm{GPa}$ \\
$\mathrm{E}_{\perp}$ & 16 & $\mathrm{GPa}$ \\
$G$ & 7 & $\mathrm{GPa}$ \\
$\nu_{\varphi z}$ & 0.26 & 1 \\
$\nu_{r \varphi}$ & 0.0756 & 1 \\
$\mathrm{UTS}$ & 1.8 & $\mathrm{GPa}$ \\
$\alpha_{\|}$ & 2.1 & $\times 10^{-6} / \mathrm{K}$ \\
$\alpha_{\perp}$ & 6.3 & $\times 10^{-6} / \mathrm{K}$ \\
\hline
\end{tabular}

Table 1: Properties of S2-glass fibre composite (filling factor 70\%) after [7]. E denotes the Young's modulus, $G$ the sheer modulus, UTS the ultimate tensile strength, $\nu$ the Poisson's ratio and $\alpha$ the thermal expansion coefficient.

\begin{tabular}{|l|c|c|}
\hline Property & Value & Unit \\
\hline \hline $\mathrm{E}_{\|}$ & $205(222)$ & $\mathrm{GPa}$ \\
$\mathrm{E}_{\perp}$ & 2.7 & $\mathrm{GPa}$ \\
$\mathrm{UTS}$ & $3.3 / 4.3$ & $\mathrm{GPa}$ \\
$\nu_{\varphi z}$ & 0.35 & 1 \\
$\nu_{r \varphi}$ & 0.0461 & 1 \\
$\nu_{r z}$ & 0.6 & 1 \\
$G$ & 1.29 & $\mathrm{GPa}$ \\
\hline
\end{tabular}

Table 2: Mechanical Properties of a Zylon-Epoxy composite (filling factor 78\%). Values in brackets are for $77 \mathrm{~K}$. E denotes the Young's modulus, $G$ the sheer modulus, UTS the ultimate tensile strength, $\nu$ the Poisson's ratio and $\alpha$ the thermal expansion coefficient.
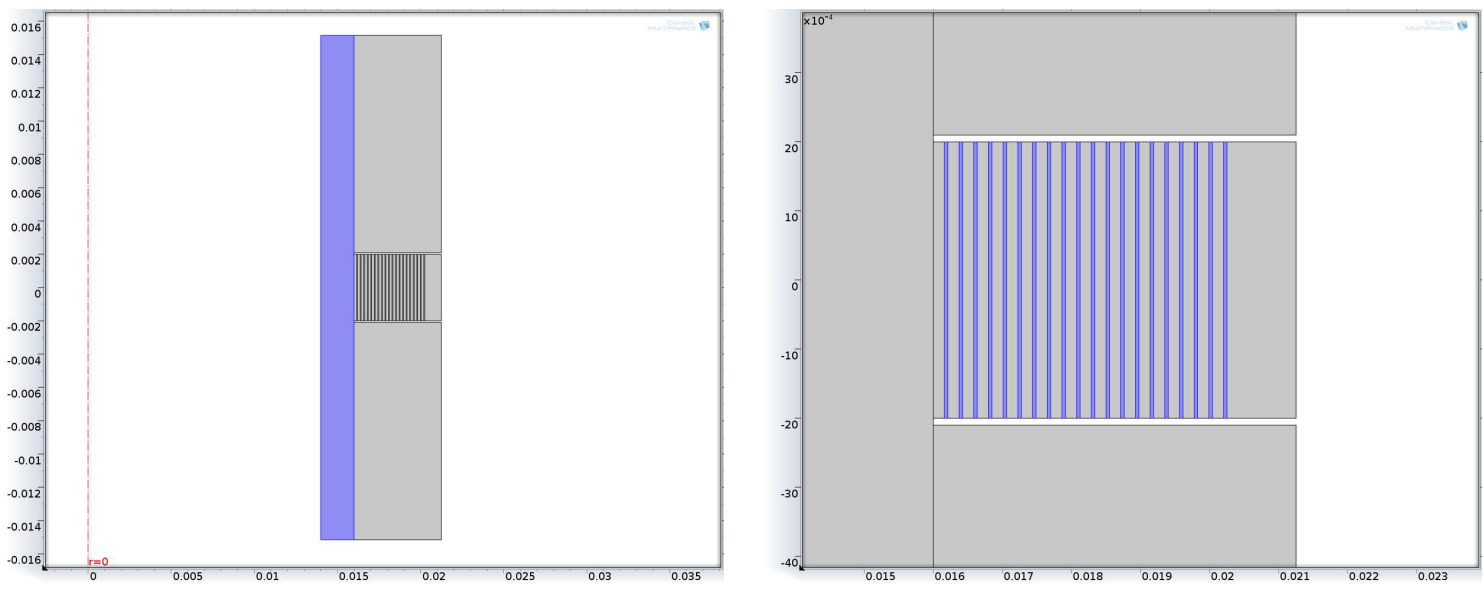

Figure 5: Overview of the simulation model. The right picture shows the winding section, where each layer of HTS tape is supported by a layer of stainless steel. 


\begin{tabular}{|l|c|c|}
\hline Property & Value & Unit \\
\hline \hline Young's modulus & $190(205-210)$ & $\mathrm{GPa}$ \\
$\nu$ & 0.28 & 1 \\
\hline UTS AISI 304 & $0.6(1.7)$ & $\mathrm{GPa}$ \\
UTS AISI 304L & $0.55(1.5)$ & $\mathrm{GPa}$ \\
UTS AISI 316 & $0.6(1.6)$ & $\mathrm{GPa}$ \\
\hline Yield strength AISI 304 & $0.2(0.5)$ & $\mathrm{GPa}$ \\
Yield strength AISI 304L & $0.05(0.2)$ & $\mathrm{GPa}$ \\
Yield strength AISI 316 & $0.25(0.7)$ & $\mathrm{GPa}$ \\
\hline$\varepsilon_{\text {break }}$ AISI 304 & $65(55)$ & $\%$ \\
$\varepsilon_{\text {break }}$ AISI 304L & $60(40)$ & $\%$ \\
$\varepsilon_{\text {break }}$ AISI 316 & $65(30)$ & $\%$ \\
$\alpha$ & 14.5 & $10^{-6} / \mathrm{K}$ \\
\hline
\end{tabular}

Table 3: Material properties of austenitic steels AISI 304/316 (L). Values in brackets are for $77 \mathrm{~K}$. $E$ denotes the Young's modulus, $G$ the sheer modulus, UTS the ultimate tensile strength, $\nu$ the Poisson's ratio and $\alpha$ the thermal expansion coefficient.
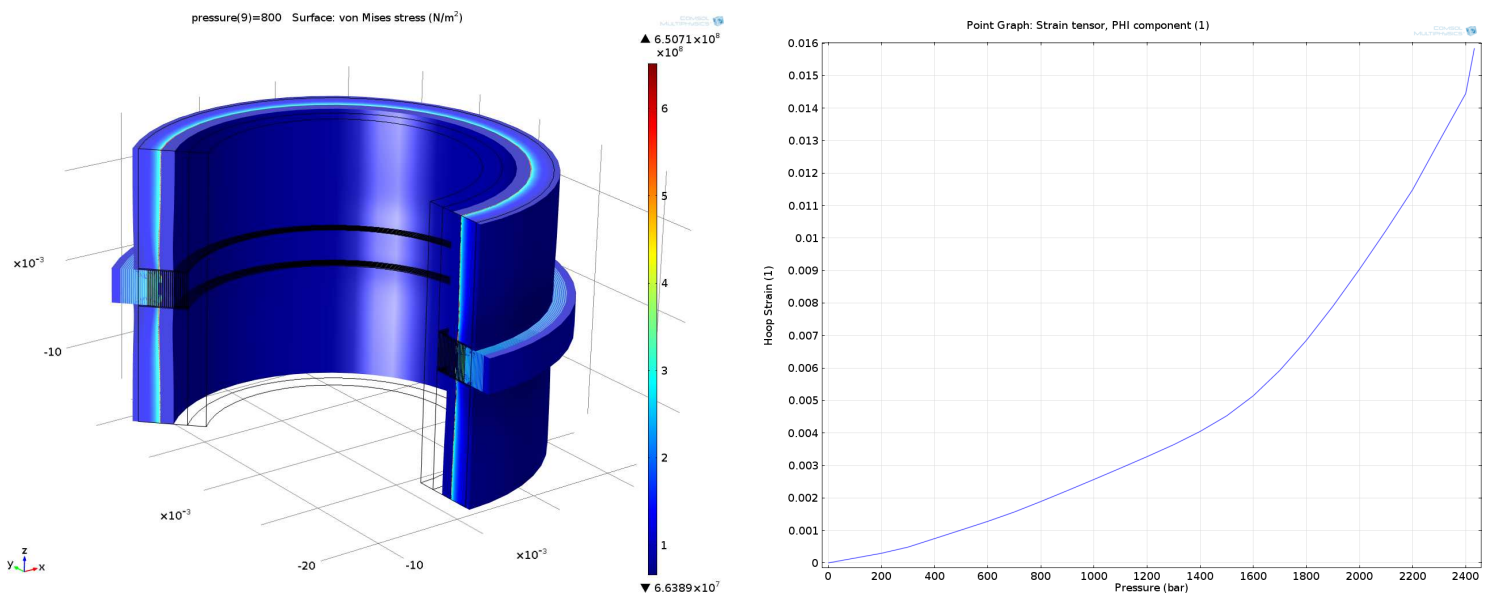

Figure 6: Example results of the finite element model. The left figure shows a 3D representation of the deformation, the right figure an example of pressure versus strain. 
The right figure shows an example plot of applied pressure on the inside of the model versus strain (on the outside of the last turn of steel tape).

\section{Test Procedure}
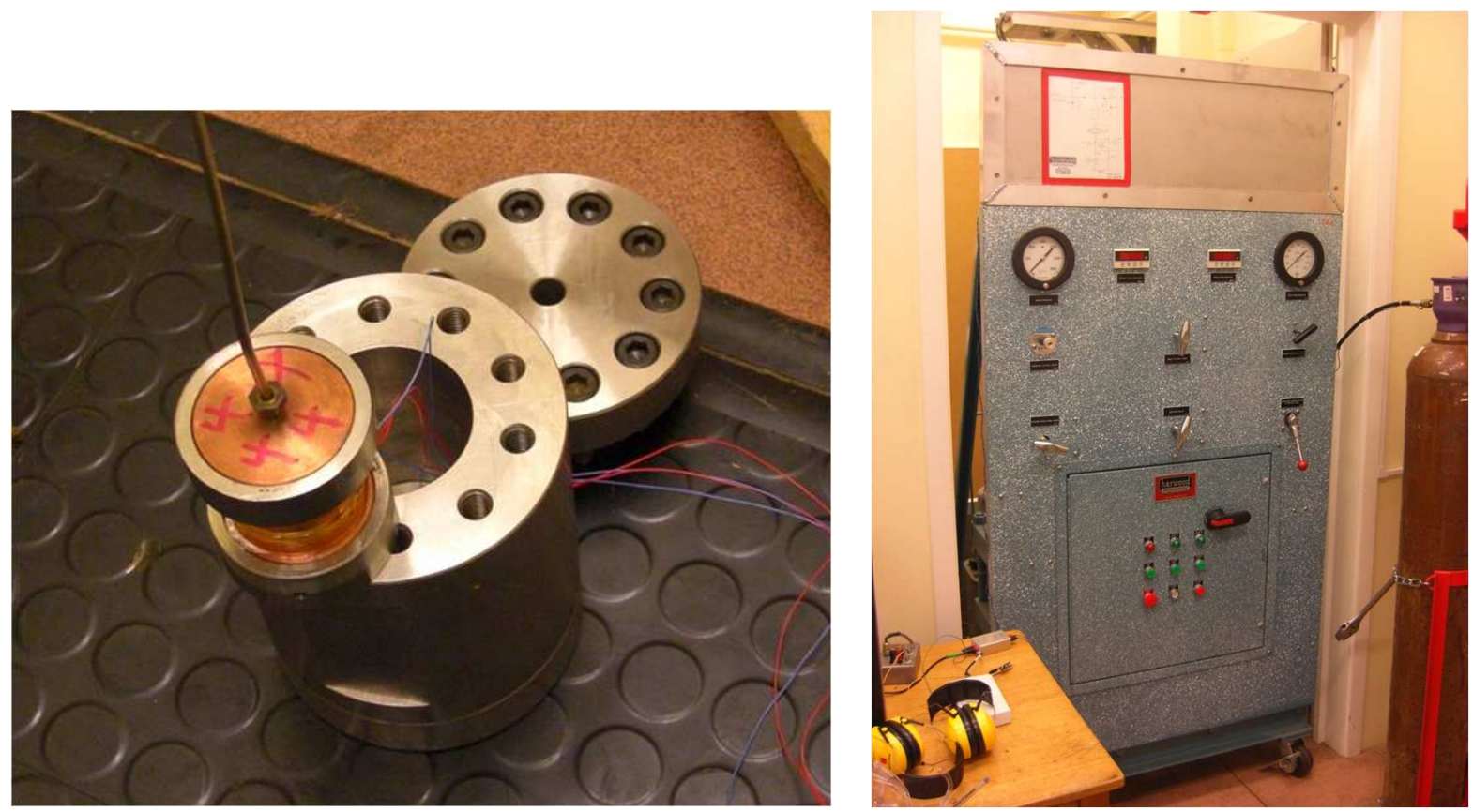

Figure 7: The figure on the left shows the prepared cell ready to go into the outer clamp. The figure on the right shows the high pressure gas rig from Harwood Engineering.

For all tests the prepared samples are mounted in the explo cell as shown in Fig. 7 (a). The cell is connected to the capillary from the Harwood Engineering high pressure rig. After mounting the pressure inside the cell is increased to about $1.5 \mathrm{kbar}$. After $1.5 \mathrm{kbar}$ is reached the valve between the $1^{\text {st }}$ and $2^{\text {nd }}$ stage is closed. The $2^{\text {nd }}$ stage is then operated until the sample ruptures.

Experiments at low temperatures were conducted as well; for this the entire clamp is placed in polystyrene bucket and immersed in liquid nitrogen. After about 30 min clamp and sample are cold, which was verified by visual inspection (no LN2 boil-off). The sample is then tested as described earlier.

One test was carried out trying to measure the resistance of the HTS coil while pressurizing the cell to determine when the superconductor (as opposed to the tape) breaks. For this one electrical contact was attached to the outside of the tape. The second contact was the copper cell itself. A current of $100 \mathrm{~mA}$ was passed though the sample; the 
voltage across the terminals was measured using the NI USB-6211 DAQ (four-terminal measurement).

\section{Results}

\subsection{Room Temperature Tests Type I}

Three cells of Type I were tested at room temperature. It was discovered early on that cells of Type I fail in an unexpected way in that the tape does not seem to rupture but rather that the tape seems to lift of from the copper cell. This is shown schematically in figure 8. To investigate this the $3^{\text {rd }}$ sample was tested in an open-clamp arrangement in an attempt to record the failure mechanism on video. Unfortunately the open clamp test failed due to insufficient strength of the tightening rods as shown in Fig. 9. Therefore data could only obtained for samples 1 and 2 .
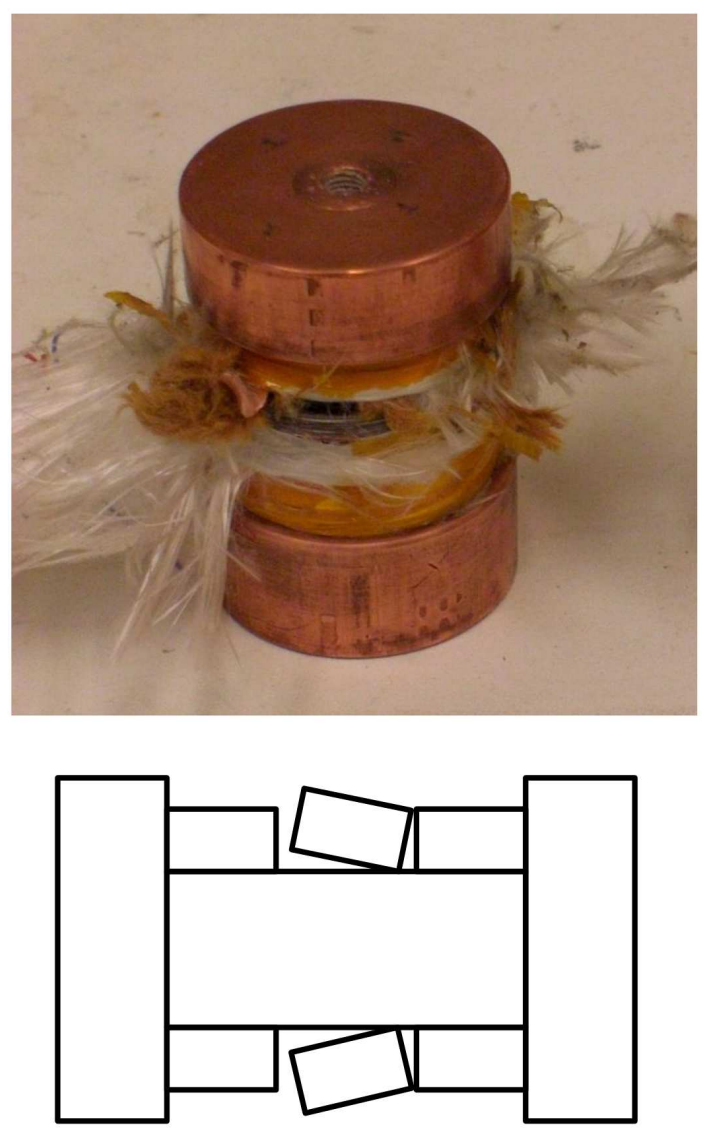

Figure 8: Failure mode of samples 1-3. 


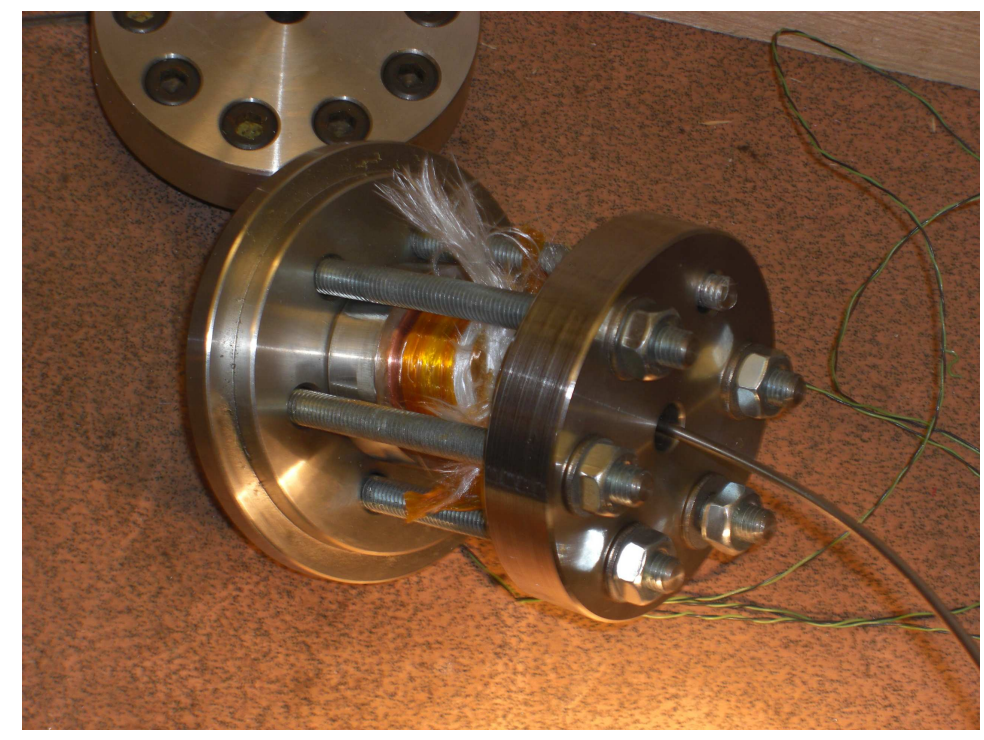

Figure 9: Open clamp test of sample 3.

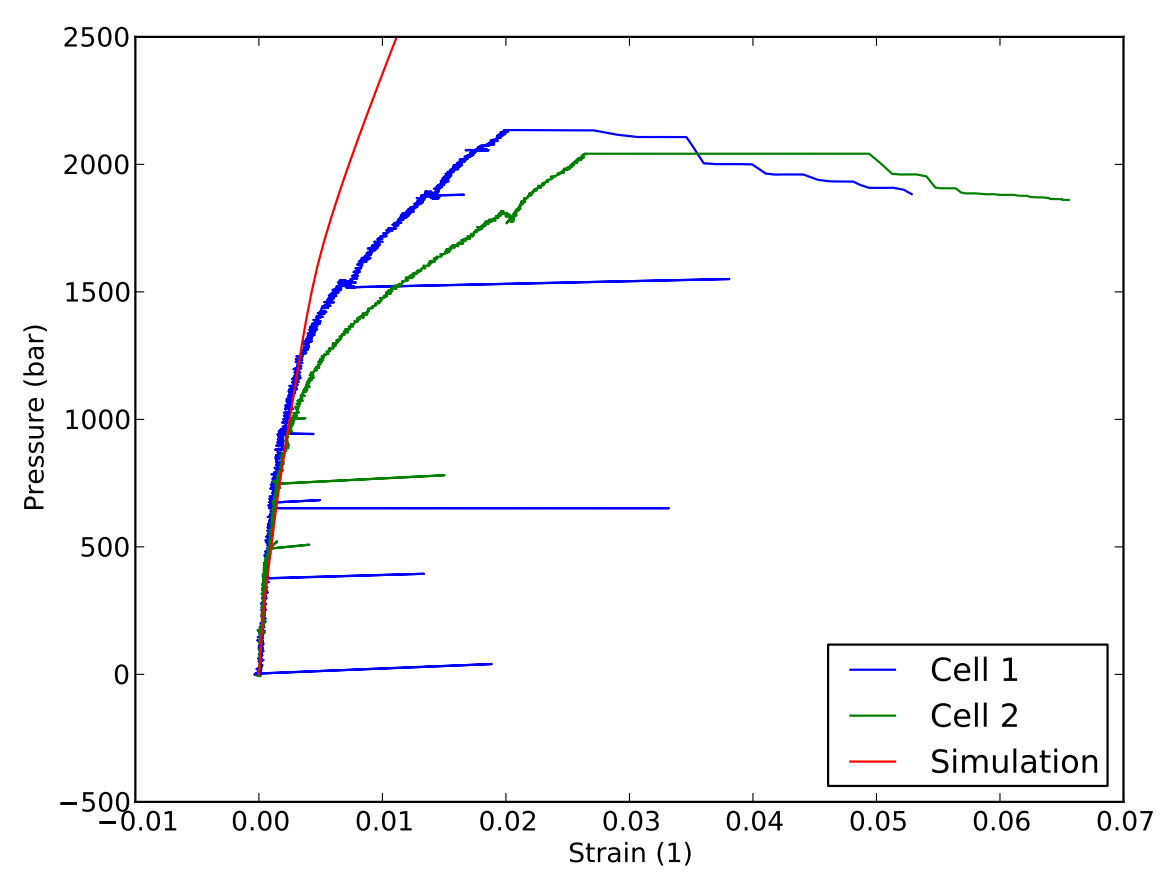

Figure 10: Results of the test of cells 1 and 2 at room temperature. Shown is also the expected result from the FEA simulation. 
The results of the test is shown in Fig. 10. The figure also shows the expected result from the FEA simulation. The figure shows that all three curves agree up to a pressure of about 1 kbar. The strain changes very little in this regime, so the curve sharply increases. Between one and two kbar all three curves differ; in general, the experimentally obtained result show much larger strains with pressure than anticipated from the FEA result, which implies a much softer structure. Both samples failed at a pressure of about 2 kbar.

\subsection{Room Temperature Tests Type II}

Two samples of Type II were tested at room temperature. The samples were found to fail as expected, that is by radially buckling outwards of the HTS/steel tape section. The failure mode is shown schematically in Fig. 11,
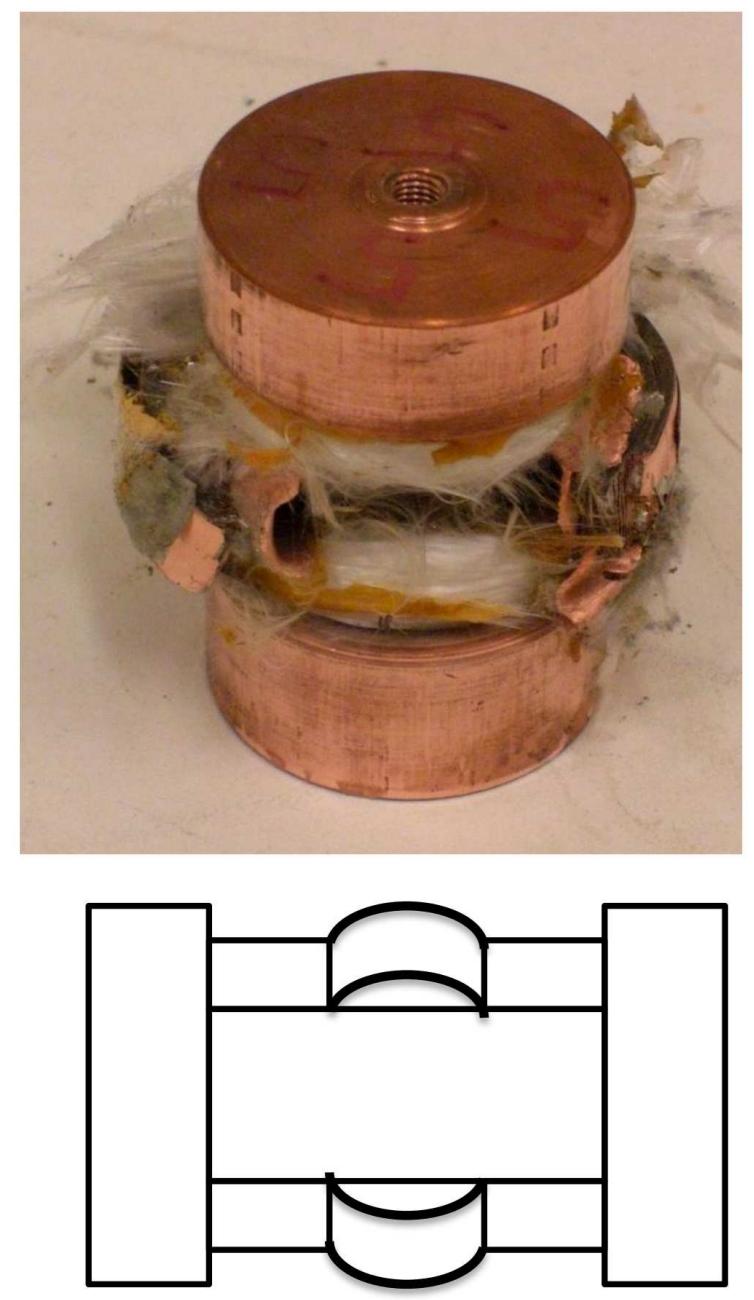

Figure 11: Failure mode of samples 4-7. 
The test results in addition to the expected result from the FEA simulation are shown in Fig. 12. The figure shows by comparison little variation between the two samples. Up to a pressure of about $1 \mathrm{kbar}$ the strain on the outside of the HTS/tape structure changes very little. From 1-1.75 kbar the strain increases more quickly; from 1.75 to 2.5 kbar the largest strain increase with pressure is observed. Up to a pressure of 1.75 kbar the FEA simulation predicts a much larger increase of strain with pressure and beyond $1.75 \mathrm{kbar}$ a smaller one than expected in the samples. In general the agreement between experimental data and the simulation is rather poor. Both samples failed at a pressure of approximately 2.5 kbar and a strain of $2 \%$.

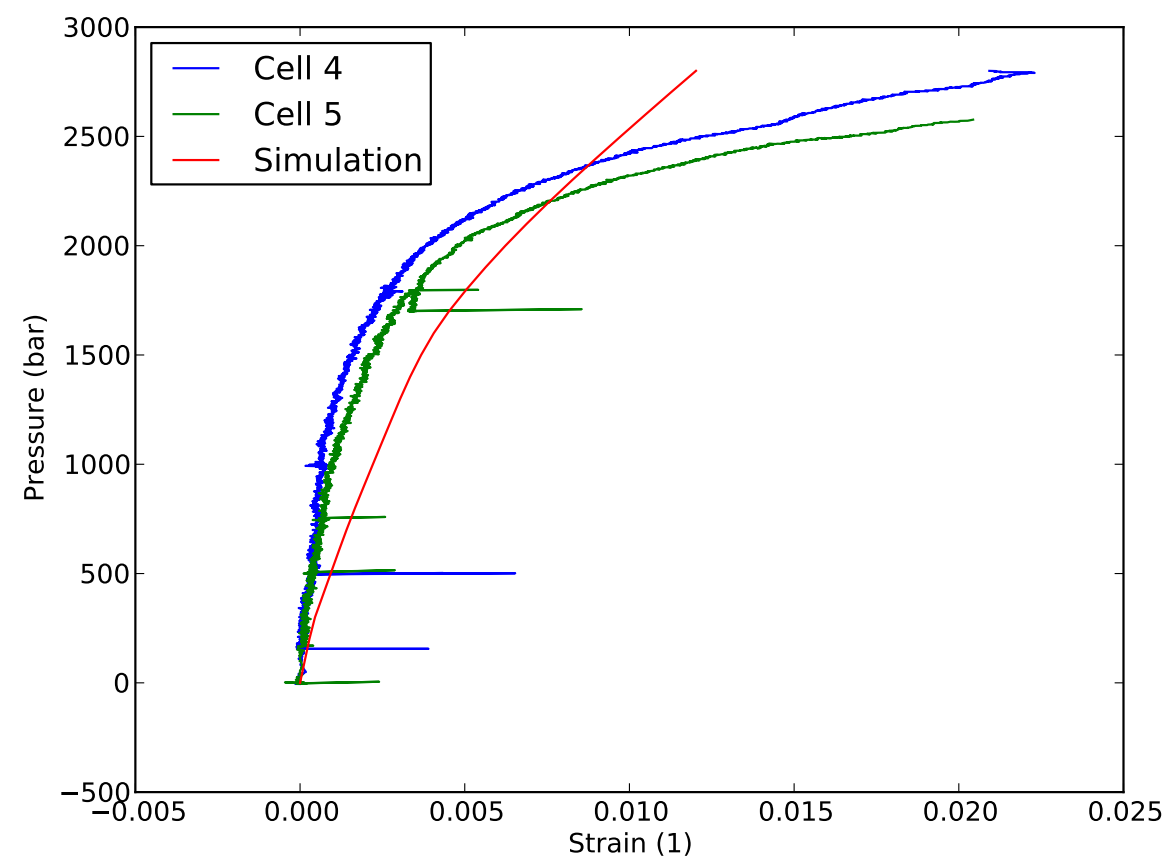

Figure 12: Results of the test of cells 4 and 5 at room temperature. Shown is also the expected result from the FEA simulation.

\subsection{Cryogenic Test Type II}

Samples 6 and 7 (Type II) were tested at $77 \mathrm{~K}$. The samples failed in a similar way to the ones at room temperature, that is by buckling of the HTS/steel section radially outwards. The results of the experiment are shown in Fig. 13, the figure also shows the expected result from the FEA simulations.

The figure shows up to a pressure of 1 kbar very little response in the strain. From approximately 1-3 kbar the strain increases more with pressure; from 3 kbar onward the 


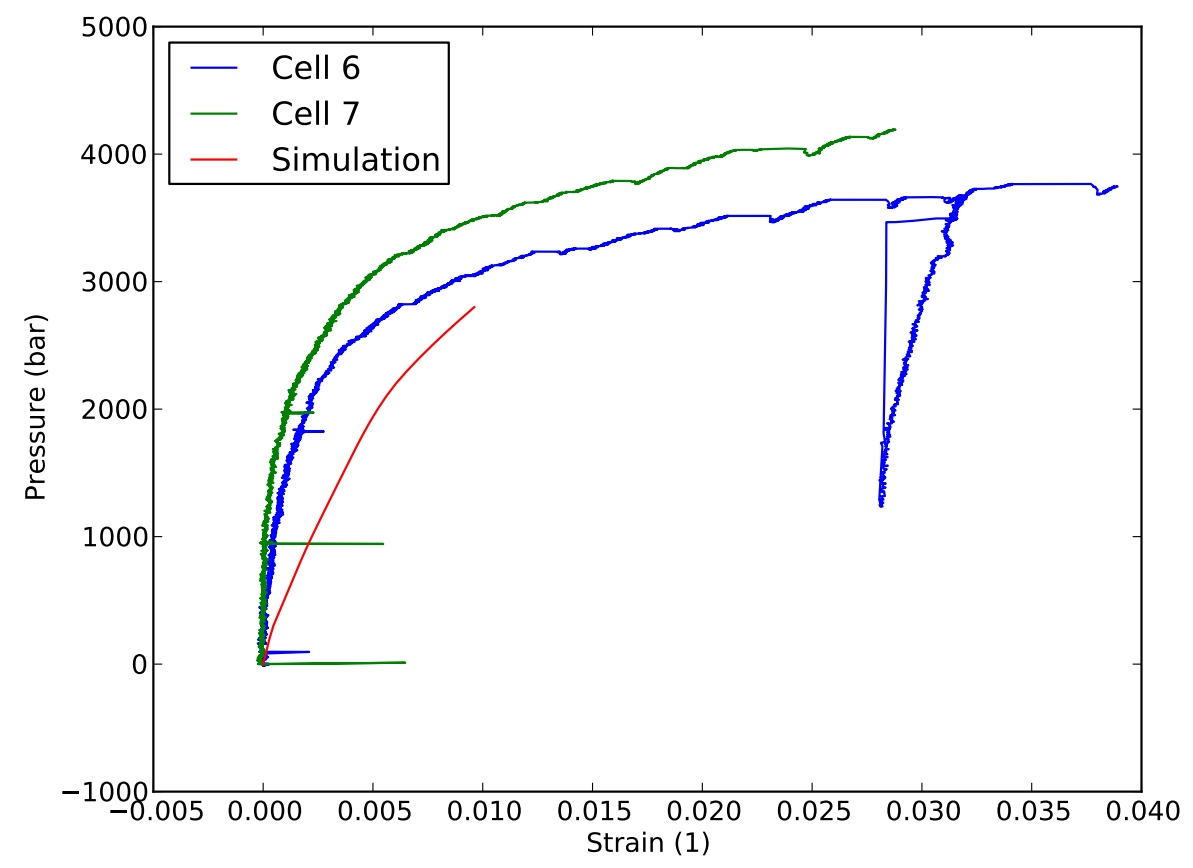

Figure 13: Results of the test of cells 6 and 7 at 77K. Shown is also the expected result from the FEA simulation. 
strain increases dramatically with a small increase in pressure. The samples failed at a pressure of about $4 \mathrm{kbar}$ and a strain of 3 and $4 \%$. The two samples show a larger difference in comparison to the two samples at room temperature. The agreement with the FEA simulations is worse than for room temperature.

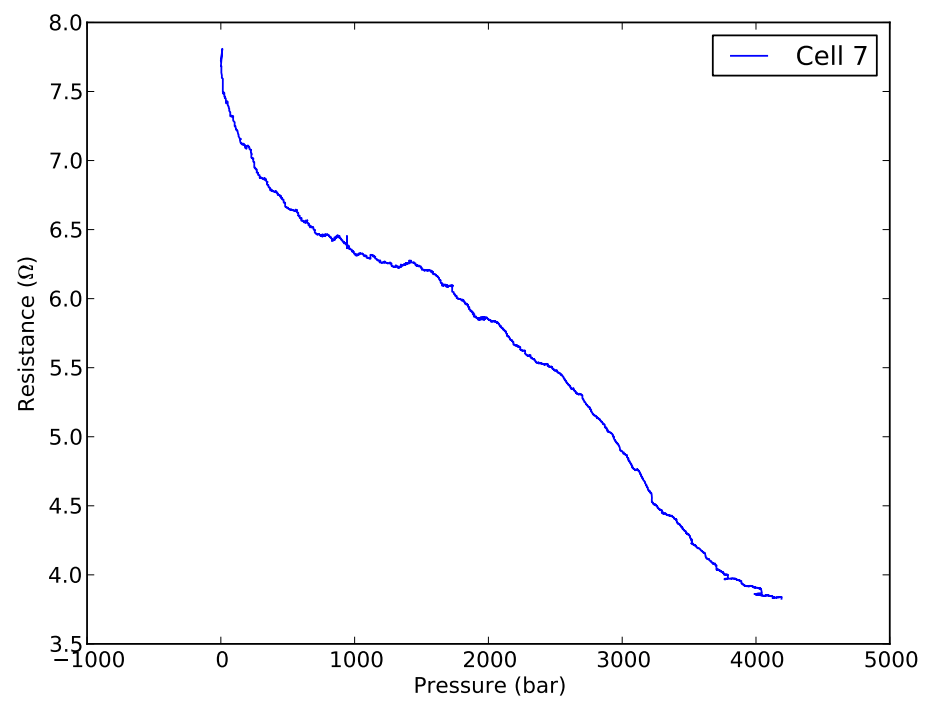

Figure 14: Result of the resistance measurement of sample 7 at $77 \mathrm{~K}$.

During the test of sample 7 it was attempted to determine when the tape stops being superconducting, which may be different from when the tape breaks. The results of the test are shown in Fig. 14. The figure shows that during the entire test the tape was normal conducting; from $0-4$ kbar the resistance decreases roughly in a linear manner from $8 \Omega$ to $3.75 \Omega$.

\section{Discussion}

In general the obtained experimental results are surprising in more than one respect:

As discussed in section 17, the failure mode of Type I samples differs from the one of Type II samples. This was consistent during the tests; while at present there is no reason to believe that this influenced the other results, the cause for this should be determined. This may have been caused by a tape with a keystone, but the tape is unavailable and can therefore not be determined anymore.

More important is the fact that the pressure at which failure occurs also differs. This can potentially be understood by the different volume ratios of different steels. In Type II samples the fraction of hastelloy is significantly higher (38\% versus $29 \%$ ). Hastelloy C276 has a higher ultimate tensile strength at room temperature than AISI 304 (700 MPa versus 
$500 \mathrm{MPa}$ ) 9, 1]. However, at lower temperatures the higher 304 ratio may be beneficial as for the UTS values of $1.5 \mathrm{GPa}$ are reported [4. Other aspects may also play a role, for example the number of turns leading to more pre-stress (29 for Type II samples versus 20 for Type I samples). Interesting is also that samples of Type I failed at a strain which is almost twice as much in comparison to Type II samples (5\% versus $2.25 \%$ ). The authors cannot explain this at the moment.

Even more surprising is the fact that at $77 \mathrm{~K}$ the strain at break for Type II samples increases to $3.5 \%$, while at the same time the bursting pressure increases by $60 \%$ to 4 kbar. Normally one would expect a decrease of the strain at break (materials become more brittle at lower temperatures) and a modest increase of the UTS of about 20-30\%. So the observed increase in strength is more than twice as much as what can be expected.

In general the FEA simulations are in poor agreement with the experimentally obtained results. A reasonable agreement can only be observed for Type I samples up to about 1 kbar. While some of the 'softer' behaviour of the samples can potentially be understood (for example at higher pressures), Type II samples seem to be stiffer than anticipated. In general, however, the authors feel that the data obtained in experiments is inconclusive and further studies are necessary to resolve this.

It is speculation, but the the behaviour could indicate that the individual layers can not be seen as one mechanical structure. For example, the inner layers could be stressed more initially, while the outer ones do not see any or very little load. This would lead to the observed behaviour. Why this would differ for Type I and II is not known.

General slippage of turns or even complete unraveling of an entire pancake was not observed during the experiments. However, steps in the pressure-strain curves as shown for example in Fig. 13 could indicate micro slips; further studies are necessary to investigate this.

For future experiments it might be advisable to redesign the exple cell to minimize or avoid the use of the high strength fibre Zylon. The present cells were designed for a different purpose, which is testing of high strength fibres. A re-designed cell could be processed more quickly, which would minimize the fabrication cost. In addition, potential error modes (for example the fibre catching the tape and therefore falsifying the results) could be avoided.

More than one strain gauge should be attached to each sample. For example, a strain gauge on the inner winding and at least one within the windings would yield a spatial distribution of the strain and could help to understand the results.

It should be attempted to determine when the superconductor itself breaks. It is unclear why the only attempt during this experimental campaign failed; a likely reason is thermal shock during cool-down, as no special precautions were made. A second attempt should be made attempting a more gentle cool-down. 


\section{References}

[1] Hastelloy alloy c-276 (uns n10276). January $2013 . \quad$ Online: http://www.hpalloy.com/alloys/descriptions/HASTELLOYC_276.html,

[2] R. Gupta. Private communication. Brookhaven National Laboratory, PO Box 5000, Upton, NY, 11973, USA, 2012.

[3] R. Gupta, M. Anerella, G. Ganetis, A. Ghosh, H. Kirk, R. Palmer, S. Plate, W. Sampson, Y. Shiroyanagi, P. Wanderer, B. Brandt, D. Cline, A. Garren, J. Kolonko, R. Scanlan, and R. Weggel. High Field HTS R\&D Solenoid for Muon Collider. IEEE Transactions on Applied Superconductivity, 21(3):1884 -1887, June 2011.

[4] B. A. Hands, editor. Cryogenic Engineering. Academic Press, 1986.

[5] Y. K. Huang, P. H. Frings, and E. Hennes. Exploding pressure vessel test on Zylon/Epoxy composite. Composites: Part B, 33:117-123, 2002.

[6] Y. K. Huang, P. H. Frings, and E. Hennes. Mechanical Properties of Zylon/Epoxy Composite. Composites: Part B, 33:109-115, 2002.

[7] D. Roylance. Laminated Composite Plates. Feb. 2000.

[8] Y. Shiroyanagi, R. Gupta, P. Joshi, H. Kirk, R. Palmer, W. Sampson, P. Wanderer, D. Cline, A. Garren, J. Kolonko, R. Scanlan, and R. Weggel. 15+ T HTS Solenoid For Muon Accelerator Program. In International Particle Accelerator Conference, pages 3617-9, New Orleans, Louisiana, USA, May 2012.

[9] M. Sugano, K. Osamura, W. Prusseit, R. Semerad, K. Itoh, and T. Kiyoshi. Tensile fracture behaviour of re-123 coated conductors induced by discontinuous yielding in hastelloy c-276 substrate. Superconductor Science and Technology, 18(12):S344, 2005.

[10] Toyobo Co. Ltd., Zylon Department, 2-2-8 Dojima-Hama, Kita-Ku OSAKA, 530-8230, Japan. PBO Fiber Zylon, 2001.9 edition, 2001.

[11] F. P. Van Sprang M, Oudendijk MGNM. Mechanical properties of woundreinforcement and fatigue properties of $\mathrm{CuAg}_{16 \%}$. In Proceedings of the Fifth International Conference on Magnet Technology, page 695, Beijing, 1998.

[12] R. P. Walsh and C. A. Swenson. Mechanical Properties of Zylon/Epoxy Composite at 295K and 77 K. IEEE Transactions on Applied Superconductivity, 16(2):1761-1764, 2006 .

[13] H. Witte. Magnet Design using Finite Element Analysis. PhD thesis, University of Oxford, 2007. 